\title{
TIM Lecture Series Intellectual Property Paradigms for Global Business
}

\author{
Gordon Freedman
}

\author{
"All decisions about patents, trademarks, and other" \\ forms of IP protection should be business decisions. \\ Don't decide based on emotion, or pride, or ego. \\ Your IP protection strategy must focus on what can \\ make you money.
}

Gordon Freedman

Entrepreneur, lawyer, and patent and trademark agent

\section{Overview}

The ninth TIM lecture of 2012 was presented by Gordon Freedman, CEO of Power Trip (powertrip.us) and lawyer at Freedman \& Associates (freedmanandassociates.ca). Freedman shared his views on intellectual property (IP) paradigms, which are based on his experiences as an entrepreneur, lawyer, and patent and trademark agent. The event was held at Carleton University in Ottawa, Canada, on November 8th, 2012.

The TIM Lecture Series is hosted by the Technology Innovation Management program (carleton.ca/tim) at Carleton University. The lectures provide a forum to promote the transfer of knowledge from university research to technology company executives and entrepreneurs as well as research and development personnel. Readers are encouraged to share related insights or provide feedback on the presentation or the TIM Lecture Series, including recommendations of future speakers.

\section{Summary}

Freedman began his presentation by describing the clash between two completely different paradigms in today's fast-paced business world. Patents and patent portfolios are being bought and sold with record valuations, and yet, many in the business community feel that patents serve little or no purpose. How can it be that something that many consider useless can be sold for so much money? The objective of the lecture was to discuss the benefits of IP protection and explore related opportunities, misunderstandings, and pitfalls, including the reasons why both of the contrasting paradigms have merit.

\section{Trademarks}

From the start, Freedman emphasized that IP protection was about more than just patents. Trademarks, for example, offer a number of benefits. Trademarks help a company protect its brands and encourage brand adoption by customers. Also, trademarks act as a repository of goodwill; customers know what to expect from the product, service, or company because of goodwill associated with a trademark. These positive associations can even be transferred to related markets as the company expands. In a well-run business, trademarks are business drivers, although some entrepreneurs make the mistake of letting the business drive the trademark. Finally, trademarks are inexpensive and easy to manage relative to other forms of IP protection.

For global businesses, however, there are downsides or at least limitations - to trademarks. While a trademark may be suitable in one market, it may not be sufficiently distinct to offer the same benefits in all markets. A trademark's meaning or even colour scheme may not translate well in other locales and may not convey the intended message in other languages. Furthermore, a similar trademark may already be in use by another company elsewhere in the world. Thus, trademarks are not global in nature, and therefore they do not automatically offer global protection. 


\section{Intellectual Property Paradigms for Global Business}

\section{Gordon Freedman}

\section{Patents}

Regarding patents, a common misconception is that they allow a business to generate revenue. Freedman pointed out that: "Patents are not about revenue, they are about downside protection. If you are making money, you don't care about patents." Thus, patents may protect the company's long-term interests against loss, particularly in large markets, but that does not mean they should be considered a business driver. For example, business and technology decisions should not be made based on what is patentable. Furthermore, beyond the large upfront costs, a company must put substantial time and money into managing a patent portfolio and monitoring potential infringement over the years, and therefore patents are not always cost effective.

\section{The pros and cons of IP}

Some see mechanisms for IP protection - especially patents - as not necessary or helpful, or as impediments to innovation. Others contend that patents encourage innovation and protect innovators by providing a reward for successful innovation. The merits of each of these opposing views may depend on the context, but there are clear advantages and drawbacks to IP, as shown in Table 1 .

In comparing the pros and cons of IP, Freedman emphasized that there is no "one size fits all" solution. In some situations, the cons of IP might outweigh the pros, and vice versa. Reasons why the balance might tip against IP include:

1. IP expends valuables resources. There can be opportunity costs associated with both the money and the time spent managing and protecting IP.
Companies should be careful that IP measures do not prevent a product launch, for example.

2. IP protection takes a long time. Companies should not protect things that will not be valuable five years from now.

3. IP is local in nature. To be effective, an IP strategy should be global. The costs associated with a global strategy can quickly become prohibitive for some companies and markets.

Reasons why the pros of IP might outweigh the cons include:

\section{IP is valuable in and of itself.}

2. IP is a tool for negotiation and profit. When a company has IP, it has more options when negotiating or deciding on business models.

3. IP can be sold or licensed. Although it is not a physical "thing", IP is property and it can be sold or used to generate revenue through licensing.

4. IP is cost effective. For companies that have access to sufficient capital, patents and other forms of IP protection are worth the cost.

5. IP is divisible. For example, a patent portfolio can be divided or sold independently from other assets.

\section{Global strategies}

Next, Freedman outlined five common strategies for protecting IP on a global scale:

Table 1. The pros and cons of IP

\section{Pros}

- IP can be monetized through sale and license

- IP leaves value if the venture fails

- IP improves competitive landscape

- IP protects future markets

- IP can bring marketing benefits

- IP-generation activities can have tax benefits

- IP has "home run" potential

\section{Cons}

- IP is expensive to acquire, protect, monitor, and enforce

- IP is risky

- IP does not prevent competition

- IP does not generate sales

- IP timelines are long

- IP needs to be managed

- IP "home runs" are rare 


\section{Intellectual Property Paradigms for Global Business}

\section{Gordon Freedman}

1. IP scattering. Spread out protection with a scattered approach across some - but not all - jurisdictions. When backed by statistical models, this strategy can be a cost-effective method of downside protection.

2. IP consolidation. Focus all efforts in one country (e.g., the United States) that allows damage claims to extend to other countries.

3. IP to protect market. File patents only in countries that have particularly strong and relevant markets.

4. IP to protect manufacture/use. Focus protection on the countries where the company makes or uses the relevant technology.

5. IP to protect corporate structure. Mitigate against the risk of key staff leaving to start their own company in a jurisdiction where the IP has been left unprotected.

\section{Conclusion}

Freedman reinforced the lessons about IP protection with In closing, Freedman offered the following tips to new entrepreneurs:

1. Look forward. Do not look back at all the great ideas from your past and wonder "What if...?"

2. Keep an innovation journal to capture ideas and notes.

3. Be very picky; focus on your best ideas.

4. In your first business, focus on the process of building a business and making money. Very few entrepreneurs make "big money" on their first real idea, but lessons from earlier attempts help them get there.

5. The only way to learn is by doing it. Every entrepreneurial lesson is a benefit in some way - even the ones that hurt.

6. Ask a lot of questions. Go the extra distance to try to understand what you do not know.

7. When faced with a business decision, do not blindly accept anything someone tells you. Everyone is motivated by self-interest and their own paradigm, which can cloud their judgement even when they have the best intentions. Make your own decisions.

\section{About the Speaker}

Gordon Freedman is an entrepreneur, lawyer, and patent and trademark agent registered to practice before the Canadian Intellectual Property Office and the United States Patent and Trademark Office. With clients ranging from early-stage technology startups to Fortune 500 companies, he brings a business-centric approach to patents and patent enforcement. Gordon honed his business acumen by founding, growing, and selling a high-tech startup; his blend of business skill and intellectual property expertise make him a unique resource. He has particular technical expertise in electronics, including semiconductor manufacturing, semiconductor circuit design, miniaturization, communications, transducer systems and information technology, including software, consumer electronics, security, image processing, and communications.

Citation: Freedman, G. 2012. TIM Lecture Series Intellectual Property Paradigms for Global Business.

Technology Innovation Management Review. December 2012: 43-45. 